\title{
Notulæ ad Plantas Japoniæ et Koreæ. III.
}

auctore

T. Nakai.

41) Panicum excurrens Trin. Sp. Gram. (1828) t. 89. Kunth Enum. Pl. I. 84. Benth. F1. Hongk. 412.

Hæc species a $P$. plicato caule multo herbaceo, foliis angustioribus et multo obscure plicatis differt.

Nom. Jap. Hime-sasakibi.

Bonin :

42) Aristida Cumingiana Trin. et Rupr. in Mém. Acad. St. Pétersb. Ser. 6. VII. (1843) 141! Steudel Syn. Glum. 140. Hook. fil. Fl. Brit. Ind. VII. 224. RendLe in Journ. Linn. Soc. XXXVI. 381.

Nom. Jap. Matsuba-shiba. (nov).

Bonin.

Planta nova ad floram Japoniam.

43) Cladium (Baumea) boninsimæ m. sp. nov.

Caulis $70 \mathrm{~cm}$. ad apicem rhizomatis terminalis et verticali inflatus. Folia verticali-inflata, radicalia brevia subvaginantia 5-1.0 cm., caulina media longissima basi vaginantia $45 \mathrm{~cm}$. longa $1 \mathrm{~cm}$. lata, plurinervia. Inflorescentia paniculata. Rhachis inflorescentiæ triangularis. Bracteæ ovatæ fusco-rubidæ. Flores in quæque fascicula 2-4. Flores præter terminales masculos v. steriles hermaphroditi. Glumæ lanceolatæ, majores dorso carinatæ. Stamina 3. Antheræ lineares acutæ. Styli trifidi, basi cum apice nucis dense barbulati.

Nom. Jap. Hira-anpera-i (nov.).

Bonin : 
Species australiensis C. Preisii huic appropinquit; sed planta est major et nux ovato-oblonga glaberque.

44) Juglans Sieboldiana Maxim. in Mél. Biol. VIII. (1872) 633. cum fig. $=$ J. coreensis Sieb. Syn. Pl. Oecon. Univ. Regni Jap. (1830) p. 27. n. 160.

Nom. Jap. Oni-gurumi.

In Japonia vulgaris.

45) Juglans cordiformis Maxim. 1. c. p. 635 cum fig.=J. Kurumi Sieb. 1. c. p. 27. n. 159.

Nom. Jap. Hime-gurumi.

In Janonia tantum culta.

46) Lindera officinalis (Sieb.).

Sassafras officinalis Sieb. 1. c. p. 23 n. 135 (excl. syn.).

Benzoin trilobum Sieb. et Zucc. Fl. Jap. Fam. Nat. II. (1846) p. 202 n. 706.

Lindera triloba BL. in Mus. Bot. Lugd. Bat. I. (1849-1851) p. 325.

Nom. Jap. Shiro-damo.

In Japonia vulgaris.

47) Euonymus Majumi Sieb. Syn. Pl. Oecon. Univ. Regni Jap (1830) p. 49. n. 267.

E. Hamiltoniana Wallich in RoxB. Fl. Ind. ed. Carey II. (1832) p. 403.

Nom. Jap. Majumi.

In Asia orientali vulgaris.

48) Elæocarpus japonicus Sieb. 1. c. p. 63 n. 330.

E. japonica Sieb. et Zucc. Fl. Jap. Fam. Nat. I. (1845) p. 165 n. 219.

Nom. Jap. Koban-mochi.

In Japonia australi vulgaris.

49) Lithospermum Murasaki Sieb. Syn. Pl. Oecon. (1830) 52. n. 191. 
L. erythrorhizon Sieb. et ZUCC. Fl. Jap. Fam. Nat. I. (1845) p. 149 n. 286.

L. arvense Thunb. Fl. Jap. (1784) p. 81 (non L.). Nom. Jap. Murasaki.

In Japonia, Korea, Mianshuria et China late expansum.

50) Ipomæa carnosa R. BR. Prodr. (1810) 485 ! Benth. Fl. Austr. III. (1869) 420. Hook. fil. Fl. Brit. Ind. IV. (1885) p. 213.

Nom. Jap. Kibana-hirugawo.

Insula Iwōtō XI. 1907. (Kawate).

Planta nova ad floram Japoniam.

51) Synedrella nodiflora GerTn. de Fruct. et Sem. II. (1791) t. 171 fig. 71 DC. Prodr. V. (1836) 629 Grisebach F1. Brit. West Ind. Isl. (1864) 377. Hook. fil. Fl. Brit. Ind. III. (1882) 308.

Verbesina nodiflora L. Amœn. Acad. IV. (1756) 290 ! WILLD. Sp. Pl. III. (1800) 2226. Dietrig Gart. Lex X. (1810) 407.

Nom. Jap. Fushizakiso. (nov.).

Bonin. (Kawate).

Planta nova ad floram Japoniam.

52) Spilanthes Acmella L. Syst. Veg. ed. XIII. (1774) 610. var. boninensis $m$. var. nov.

Cum forma depauperata S. Acmellanæ similis, sed caulis ramosissimus, pedunculi breviores.

Nom. Jap. Hime-sennichi-modoki (nov.).

Bonin. (Kawate) 